\title{
The Effect of Giving Intervention 12 Balance Exercise on Postural Balance in Elderly
}

\author{
Ninik Murtiyani, Hartin Suidah \\ Department of Nursing, Nursing Academy Dian Husada, Mojokerto, Indonesia \\ Email: ninik.akbar@yahoo.co.id
}

How to cite this paper: Murtiyani, N. and Suidah, H. (2019) The Effect of Giving Intervention 12 Balance Exercise on Postural Balance in Elderly. Open Journal of Nursing, 9, 534-540. https://doi.org/10.4236/ojn.2019.95045

Received: April 9, 2019

Accepted: May 26, 2019

Published: May 29, 2019

Copyright (อ 2019 by author(s) and Scientific Research Publishing Inc. This work is licensed under the Creative Commons Attribution International License (CC BY 4.0).

http://creativecommons.org/licenses/by/4.0/ (c) (i) Open Access

\begin{abstract}
Elderly is an age group that has a high risk of experiencing health problems. One risk that can be experienced by the elderly is the risk of falling. One of the risk factors for falling in the elderly is decreasing in postural balance of the elderly. One of the non-pharmacological therapies developed to reduce the risk of falling in the elderly is to improve the ability of the elderly, especially in controlling postural balance. The purpose of this study was to determine the effectiveness of 12 balance exercises to improve postural balance in the elderly. This type of research is quasi experiments with static group comparison. The research data are obtained by researchers using observation sheet, then the data are tabulated. This study involved two research groups namely the control group (the group not given the intervention) and the treatment group (the group that was given the 12 balance exercise intervention). From the results of Paired samples, t-test with significance level $\alpha=$ 0.05 is obtained by the significance value (p) of 0.025 . This study shows that the provision of 12 balance therapy exercise strategy is effective to improve postural balance in the elderly as a preventive effort from the risk of falling.
\end{abstract}

\section{Keywords}

Elderly, Postural Balance, 12 Balance Exercise

\section{Introduction}

Elderly is a condition which is an advanced stage of the life process characterized by a decrease in the body's ability to adapt to environmental stress. Decreasing the ability of various organs, functions and systems of this body is physiological [1]. The phenomenon that often occurs in the elderly especially in the musculoskeletal system is osteoporosis, rheumatoid arthritis and most fractures cause falls in the elderly as a result of decreased gait/balance. Postural balance disord- 
ers are things that often occur in the elderly. If the postural balance of the elderly is not controlled, it can increase the risk of falling. Physical exercise in the form of balance training of the elderly is needed to reduce the possibility of falls. Because falling further complications are death [2].

The Central Bureau of Statistics Indonesia report the life expectancy increased in 2010, the elderly population was $7.56 \%$ and in 2011 it was $7.58 \%$. Meanwhile, the Indonesian Health Profile Source in 2012 illustrates the proportion of elderly in Indonesia of $7.6 \%$ or around 18.5 million people. The United Nations, World Population Prospect stated that in 2013 the number of elderly people in Indonesia had increased to $8.9 \%$. About $30 \%-50 \%$ of the elderly population (aged 65 years) and above experience falls every year [3]. Falling incidents in Indonesia recorded that of 115 orphanage residents' as many as 30 elderly or around $43.47 \%$ had fallen. Based on data found in the Panti Werdha Hargodelali Surabaya, it was found that $60 \%$ of the 39 residents of the orphanage had experienced a fall in 2011, the fall resulted in 3 elderly from 23 falling elderly being treated in hospital because 2 elderly had femoral fractures and 1 elderly had pelvic fracture and the rest were treated by the orphanage alone because there was only bruising and sprains [4]. The results of the initial data collection conducted by researchers at 10 elderly people, data was obtained, as many as 8 elderly people had experienced falls when they were doing activities.

The risk of falling during an activity can be experienced by all ages. The older a person is, the more risk of falling incidents will be. One of the causes of falls in the elderly is the occurrence of postural disorders caused by the aging process, the disease experienced, and a decrease in bodily functions. Falling incidents experienced by the elderly can result in fractures, muscle disorders and the most fatal risk is death [5]. Postural balance disorders occur due to a decrease in the number and size of muscle fibers (muscle atrophy). Decreasing the number and size of muscle fibers will have an impact on the decrease in the musculoskeletal system which triggers a decrease in the ability of the sarcoplasmic reticulum to release calcium (Ca). This also has an impact on the not optimal pulling force between actin and myosin which ultimately results in contractions and causes the balance in the body not to be formed properly. The risk of falling in the elderly is also influenced by the presence of gait disorders, weakness of the lower muscle extremities and joint stiffness [2]. Decrease in muscle mass, connective tissue stiffness causes a decrease in muscle strength, especially in the extremities which result in slowness in moving feet that cannot tread firmly and tend to be easily shaken. Decreased muscle strength also causes a decrease in mobility in the elderly. Because muscle strength is a major component of the ability to step, walk and balance [6].

Various therapeutic treatments both pharmacological and non-pharmacological began to be developed to reduce the risk of falls in the elderly. To reduce the risk of falling in old age, the Ministry of Health of the Republic of Indonesia through aging, healthy and active program. This aims to improve the quality of life of the 
elderly and reduce the rate of dependence on the elderly in the family. One of the efforts made is to avoid the elderly from the risk of degenerative diseases and various other disorders including the risk of falling. The non pharmacology method developed to reduce the risk of falling in the elderly is to use the 12 balance strategy exercise technique. The 12 balance strategy exercise has benefits for increasing functional stability limits, improving motor systems, improving postural control, and increasing dynamic stability. But this technique also has a negative impact on the elderly when applied so that the implementation is needed by the supervisor [7].

The purpose of this study was to determine the effectiveness of 12 balance exercises to improve postural balance in the elderly.

\section{Methods}

This type of research is quasi experiments with static group comparison study design which in practice is used two groups: Treatment using 12 balance exercise strategy and without exercises. Respondents involved in this research activity must meet the research criteria determined by the researcher, namely: 1) is an elderly group, 2) has fallen during an activity, 3) has no physical problems such as a disability in the body or visual impairment, 4) can communicate well. The instrument of data collection used is the observation sheet adopted from Berg Balance Scale. This measurement consists of 14 types of static balance tests or dynamic on a scale of 0 - 4 (scale based on quality and time) required to complete the test) [8]. The research data were collected twice. Preliminary data collected using Berg Balance Scale was used as the initial data (pre-test). The research group given treatment uses a 12 balance exercise strategy, given exercise training for a period of 3 months. Exercise is given once a day and is supervised by the research team. In each meeting session, the research team also provides health education to the respondents so that they always try to do physical activities so that their health condition can be maintained. In other research groups that were not given 12 balance exercise strategy training, researchers only provided health education to respondents to always try to do physical activities to maintain their health condition. After a period of 3 months from the initial data collection (pre-test), the researcher collected data again regarding postural balance in the elderly using Berg Balance Scale and used as the final data (pre-test). The results of the research data that have been obtained are then tabulated for further data analysis. Analysis of the data used using the Wilcoxon test.

\section{Ethical Clearance}

This study was approved by the local ethics commissions are derived from hospital institutions Wahidin Sudiro Husodo Mojokerto. This study was approved by the local ethics commissions are derived from hospital institutions Wahidin Sudiro Husodo Mojokerto (033/RSU/EC/IV/2018). For the determination of the area used as a study was approved by the Research Commission Mojokerto. 


\section{Results}

1) Sociodemographic and clinical characteristics of the participants.

The results of research conducted for social demographics and respondent characteristics of the research are presented in Table 1.

2) Effectiveness of 12 balance exercise on postural balance in the elderly.

Data that has been collected using Berg Balance Scale, it can be concluded that the group of respondents given the 12 balance exercise intervention experienced an increase in postural balance of 1.53770 . This result is higher when compared to changes in postural balance experienced by groups of respondents who were not given intervention with a result of 0.17264 . From the Paired samples t-test analysis obtained significance value of 0.025 so the research hypothesis is accepted which means intervention 12 balance exercise effective to improve the postural balance in the elderly (Table 2, Table 3 ).

Table 1. Sociodemographic and clinical characteristics of the participants.

\begin{tabular}{|c|c|c|c|c|c|}
\hline \multirow{2}{*}{ No } & \multirow{2}{*}{ Characteristic } & \multicolumn{2}{|c|}{ Group with treatment } & \multicolumn{2}{|c|}{ Group without treatment } \\
\hline & & $\mathrm{N}$ & $\%$ & $\mathrm{~N}$ & $\%$ \\
\hline \multirow{4}{*}{1} & Age & & & & \\
\hline & - Middle age (45 - 59 years old) & 3 & $8.8 \%$ & 4 & $11.8 \%$ \\
\hline & - Elderly (60 - 74 years old) & 25 & $73.5 \%$ & 22 & $64.7 \%$ \\
\hline & - Old (75 - 90 years old) & 6 & $17.6 \%$ & 8 & $23.5 \%$ \\
\hline \multirow{3}{*}{2} & Sex & & & & \\
\hline & - Man & 16 & $47.1 \%$ & 20 & $58.8 \%$ \\
\hline & - Women & 18 & $52.9 \%$ & 14 & $41.2 \%$ \\
\hline \multirow{3}{*}{3} & Work activities & & & & \\
\hline & - Active work & 24 & $70.6 \%$ & 22 & $64.7 \%$ \\
\hline & - Not actively working & 10 & $29.4 \%$ & 12 & $35.3 \%$ \\
\hline \multirow{4}{*}{4} & Blood pressure & & & & \\
\hline & - Pre-hypertension & 6 & $17.6 \%$ & 8 & $23.5 \%$ \\
\hline & - First degree hypertension & 24 & $70.6 \%$ & 20 & $58.8 \%$ \\
\hline & - Second degree hypertension & 4 & $11.8 \%$ & 6 & $17.6 \%$ \\
\hline
\end{tabular}

Table 2. Paired samples statistics.

\begin{tabular}{ccccc}
\hline & \multicolumn{2}{c}{ Group with treatment } & \multicolumn{2}{c}{ Group without treatment } \\
\cline { 2 - 4 } & Pre-test & Post-test & Pre-test & Post-test \\
\hline Mean & 26.1176 & 26.7353 & 25.9706 & 26.2941 \\
Std. Deviation & 6.23171 & 6.64379 & 6.31250 & 6.06795 \\
Std Error Mean & 1.06873 & 1.13940 & 1.08258 & 1.04064 \\
\hline
\end{tabular}

Table 3. Paired samples test.

\begin{tabular}{ccc}
\hline & Group with treatment & Group without treatment \\
\hline Mean & -0.61765 & 1.00666 \\
Std. Deviation & 1.53770 & 0.17264 \\
Lower & -1.15418 & -0.67477 \\
\hline
\end{tabular}


Continued

\begin{tabular}{ccc}
\hline Upper & -0.08112 & 0.02771 \\
$\mathrm{t}$ & -2.342 & -1.874 \\
$\mathrm{df}$ & 33 & 33 \\
Sig. (2-tailed) & 0.025 & 0.070 \\
\hline
\end{tabular}

\section{Discussions}

From the results of the study, it was found that the elderly group of respondents given the 12 balance exercise intervention experienced an increase in postural balance with a significance value of 0.025 .

The provision of 12 balance exercise intervention has the same mechanism in improving dynamic balance in the elderly by maintaining the limit of stability, activating the system feedback on movement strategies, and increasing dynamic stability. The 12 balance exercise training has the advantage of improving dynamic balance, making this training more effective. The 12 balance exercise training activates the feedforward mechanism in movement strategies and enhances sensory strategies in the form of sensory integration and sensory re-weighting [8].

The vestibulocerebellum (cerebellum) system is useful for regulating the balance between the contraction of agonist muscles and antagonistic muscles in the back, pelvis, and shoulders when the body's position changes rapidly thus needed by the vestibular apparatus. In the stepping exercise training in the 12 balance exercise, it activates the vestibulocerebellum function which acts to calculate the speed of the next movement and the direction in which various body parts will be for the next few milliseconds. The results of this calculation are the key to the brain's progress for the next sequence of motion [9]. During balance regulation, it is estimated that information originating from the peripheral part of the body and vestibular apparatus is used by a feedback regulation circuit specifically to provide anticipated correction of motor signals. Anticipation correction activates the feedforward mechanism for correction of the attitude needed to maintain balance when there is very fast movement, including rapid changes in direction of movement [10].

Sensory integration in the 12 balance exercise training is achieved through eye tracking, dynamic walking, and stepping exercise training [11]. When doing eye tracking training and stepping exercise activates the vestibulo ocular reflex. Stepping exercise training also gives rise to excitation in the vestibular apparatus, in this case, the semicircular canal, and dynamic walking provides additional information on the body's somatosensory, so that the concept of sensory integration is achieved in terms of maintaining dynamic balance, namely: Integration between the visual, vestibular and somatosensory systems [12]. In an effort to optimize the function of the organs that are important for maintaining postural balance in the elderly, therapy is needed continuously and in a certain period of time. Support from various parties such as health workers as therapists and family members to provide support and mentoring as long as the elderly undergo 
therapy sessions will make the results of the therapies more optimal and will eventually help the elderly in their efforts to improve postural balance [13].

In an effort to improve health of the elderly, participation from various parties is needed to provide support to the elderly in their efforts to achieve the goal of improving health. The risk of falling during an activity in the elderly is a natural condition to occur in the elderly considering that at the age of the elderly, the organs of the body begin to experience a decline in function and ability. The provision of a 12 balance exercise intervention is a preventive effort that can be done to improve postural balance in the elderly which in turn will trigger elderly independence in carrying out activities.

\section{Conclusion}

The results of the research conducted to prove that the provision of 12 balance exercise interventions in the elderly is effective in helping the elderly to improve their postural balance and reduce the risk of falling in the elderly while doing activities.

\section{Acknowledgements}

This research was supported by the Republic of Indonesia Ministry of Research, Technology and Higher Education.

\section{Conflicts of Interest}

The authors declare no conflicts of interest regarding the publication of this paper.

\section{References}

[1] Pudjiastuti, S.S. and Utomo, B. (2003) Physiotherapy in the Elderly. EGC Medical Book Publishers, Jakarta, Indonesia.

[2] Darmojo, B. and Martono, H. (2004) Geriatric Textbook. Hall of Publishers of the Faculty of Medicine, Jakarta, Indonesia.

[3] Nugroho, W. (2008) Gerontik and Geriatric Nursing. EGC Medical Book Publishers, Jakarta, Indonesia.

[4] Afidah, F., Dewi, Y.S. and Hadisuyatmana, S. (2019) Risk Study Fall Through Examination of Dynamic Gait Index (DGI) for the Elderly at the Surabaya Hargodedali Nursing Home. Indonesian Journal of Community Health Nursing, 1, 1-13.

[5] Avers, L., Mathur, A. and Kamat, D. (2007) Music Therapy in Pediatrics. Clinical Pediatrics, 46, 575-579. https://doi.org/10.1177/0009922806294846

[6] Guccione, A.A. (2000) Implications of an Aging Population for Rehabilitation: Demography, Mortality and Morbidity in the Elderly. In: Guccione, A.A. Ed., Geriatric Physical Therapy, 2nd Editions, St. Louis, Mosby, pp. 3-16.

[7] Kisner, C., Colby, L.A. and Borstad, J. (2017) Therapeutic Exercise: Foundations and Techniques. F.A. Davis Company, Philadelphia, Pennsylvania.

[8] Kornetti, D.L., Fritz, S.L., Chiu, Y.P., Light, K.E. and Velozo, C.A. (2004) Rating Scale Analysis of the Berg Balance Scale. Archives of Physical Medicine and Reha- 
bilitation, 85, 1128-1135. https://doi.org/10.1016/j.apmr.2003.11.019

[9] Kaesler, D.S., Mellifont, R.B., Kelly, P.S. and Taaffe, D.R. (2007) A Novel Balance Exercise Program for Postural Stability in Older Adults: A Pilot Study. Journal of Bodywork and Movement Therapies, 11, 37-43. https://doi.org/10.1016/j.jbmt.2006.05.003

[10] Nugraha, M.H.S. and Kebudayaan, K.P.D. (2016) 12 Balance Exercise Training Increases Dynamic Balance More Than Balance Strategy Exercise in the Elderly in Banjar Bumi Shanti, Dauh Puri Kelod Village, West Denpasar District.

[11] Wibowo, A.B. (2017) The Effect of Gaze Stabilization Exercise And Balance Exercise on Increasing Analysis Balance in Age Community in Trenggalek District. University of Muhammadiyah Malang, Malang, Indonesia.

[12] Rahmanto, S. (2017) The Effectiveness of The Stretching Exercise Program, Kinesthesia Exercise and Balance Exercise under the Breaks on Pain Reduction and Enhancement of the Osteoarthritis Patient Rom.

[13] Setyoadi, S., Utami, Y.W. and Septina, S. (2013) Gymnastics Can Improve the Balance of the Body of the Elderly in the Gerontology Foundation in Wajak District, Malang Regency. Journal of Nursing, 1, 35-40. 